\title{
Board 5: Construction Engineering Division: Tailoring Construction Man- agement Instruction to the Emerging Adult Learner
}

\section{Dr. Robert B Austin P.E., Bowling Green State University}

Dr. Austin has over 30 years of heavy construction, engineering and facility experience in industrial, transportation and building projects across the full range of project delivery systems. His industry experience is multi-faceted with a strong background in civil engineering and construction management on both domestic and international projects. Having served in responsible charge of projects nationwide, he possesses professional engineering licenses in several states. During his professional tenure he has received awards for construction innovation, superior project performances and one of the projects, a rebuild of a university campus, received industry recognition a project of the year. Dr. Austin earned his Bachelors and Masters in Civil Engineering from the University of Connecticut and University of Texas. He recently earned his Doctorate in Construction Management from the Georgia Institute of Technology where his research focus was on accelerated project deliveries (i.e., faster, more predictable fast-track construction). His publications include a selection of industry articles on concrete technology, project management, safety and quality management. His academic research and writings have been on concrete repairs, structural plastics and flash track project management were funded by the American Society of Civil Engineers and the Construction Industry Institute. Dr. Austin's teaching and research interests cross the spectrum of the construction management, with a current focus on project management, construction equipment, planning and scheduling and research and teaching methodologies. 


\section{Tailoring Construction Management Instruction to the Emerging Adult Learner}

\section{Dr. Robert B. Austin, Bowling Green State University}

Dr. Austin has over 30 years of heavy construction, engineering and facility experience in industrial, transportation and building projects across the full range of project delivery systems. His industry experience is multi-faceted with a strong background in civil engineering and construction management on both domestic and international projects. Having served in responsible charge of projects nationwide, he possesses professional engineering licenses in several states. During his professional tenure he has received awards for construction innovation, superior project performances and one of the projects, a rebuild of a university campus, received industry recognition a project of the year. Dr. Austin earned his Bachelors and Masters in Civil Engineering from the University of Connecticut and University of Texas. He earned his Doctorate in Construction Management from the Georgia Institute of Technology where his research focus was on accelerated project deliveries (i.e., faster, more predictable fast-track construction). His publications include a selection of industry articles on concrete technology, project management, safety and quality management. His academic research and writings have been on concrete repairs, structural plastics and flash track project management were funded by the American Society of Civil Engineers and the Construction Industry Institute. Dr. Austin's teaching and research interests cross the spectrum of the construction management, with a current focus on project management, construction equipment, planning and scheduling and research and teaching methodologies. 


\section{Tailoring Construction Management Instruction to the Emerging Adult Learner}

Introduction

According to the National Survey of Student Engagement [29], Bowling Green State University (BGSU) is a national leader in providing opportunities in experiential education. This commitment has been echoed by the University's new president, Rodney Rogers, as he announced that BGSU goes beyond "active learning.” BGSU has been involved in cooperative education programs for more than fifty years and requires students to have three supervised cooperative education experiences. In addition to offering real-world experiences, these cooperative education opportunities are expected to help students transition to becoming adult life-long learners. This paper describes the experience and challenges encountered in engaging in and promoting adult education principles in the undergraduate construction management curriculum.

The principles of adult education mesh well with construction management students' instructional preferences, including having instructors solicit input from students and tailoring instruction to student interest, readiness, and willingness to engage in the classroom [1, 19, 24]. In adult education theory, individual maturation steadily increases a person's need and capacity to be self-directing and an individual's self-concept moves from dependence to autonomy [21]. Knowles [22] and others [6, 8, 9] noted that the teacher is the most important factor influencing the nature of the learning climate and that a collaborative approach is most effective and appropriate for teaching adults.

Using adult learning practices with traditional students may promote achievement of program learning goals as well as life-long learning. At BGSU, we have begun a process to introduce adult learning strategies in selected courses. We reconsidered instructional approaches based on prior experience and feedback on industry needs. This led to more problem-based assignments, discussions of the practical relevance of course content, and a participatory approach to instruction to address challenging concepts. Participatory instructional approaches have included identification of knowledge gaps, extending autonomy in the selection of assignments, and discussions on effective learning strategies to meet the instructional learning objectives. To communicate the practical relevance of course topics, we propose critical thinking exercises to help students understand the sequencing of construction activities, construction risks and mitigation measures, and decision making. 


\section{Literature Review}

A literature search was undertaken on adult education, student motivation, instructional methods for threshold concepts, and basic learning strategies.

Andragogy refers to adult learning and education. The term has a long history, beginning with Alexander Kapp who coined the term in 1833. Eduard C. Lindeman popularized it in 1926 and then Malcolm Knowles promoted it more widely in the 1960s and 1970s [6]. Knowles defined adult education as the art and science of teaching adults, noting that adult learning (andragogy) is distinct from child learning (pedagogy). Andragogy is based upon six assumptions: (a) selfdirectedness, (b) need to know, (c) use of experience in learning, (d) readiness to learn, (e) orientation to learning, and (f) internal motivation [6, 12, 21]. Knowles [23] contended that "andragogy works best in practice when it is adapted to fit the uniqueness of the learners and the learning situation.”

In an andragogical approach, an instructor tailors instruction to meet student interest by involving the students in planning the learning objectives and activities and in solving real-world problems. As a result, the approach promotes trust between the student and the instructor and enhances student self-awareness. Adult learners set their own pace and put a personal structure on their learning; show a high degree of control over the planning and management of learning; can effectively locate and use a variety of resources; are able to organize and make the best possible use of time; and see themselves as competent and effective and direct their own learning confidently [34]. Pratt [34] further discussed that much of the writing and discussion about andragogy is based on the assumption that adults should be taught collaboratively.

Conti [8, 9] offered a slightly differing perspective that complements Knowles' flexible approach, reporting that adult students' preference for a learner-centered or student-centered instructional approach was situational. In cases where adults are focused on short-term needs, such as passing an examination, they prefer a teacher-centered approach and in cases where they seek skills development they prefer a student-centered approach.

Student engagement and andragogy share a number of elements. Both entail (a) a learnercentered curriculum, (b) learning activities related to the learner's experiences, (c) self-direction, (d) learner involvement in entrance and exit assessments, (e) problem-centered instruction, and (f) an instructor who serves ideally as a facilitator [6]. Forrest and Peterson [16] claim that the andragogical approach is essential in management education to prepare students for their future working environments.

The traditional undergraduate management student, aged 18 to 25 years, is in a phase of life development known as emerging adulthood. These traditional students are different from mature adults in many ways [13]. Traditional students are often ill-prepared to take ownership of their education, often lacking intrinsic motivation to learn, and they sometimes struggle with difficult 
to learn or threshold concepts. The notion of emerging adulthood is consistent with results from surveys of college students in which only about $25 \%$ consider themselves to be adults [2, 30].

Dachner and Polin [12] identified adult education principles that can be effectively applied with emerging adults. Emerging adult students’ self-concept changes as they mature from being dependent on others to being dependent on themselves. Emerging adults may have sufficient life and work experiences to benefit from only practical application in the classroom. They become ready to learn when they recognize that what they are learning is related to their current roles and responsibilities. However, in their orientation to learning, emerging adults may not have welldeveloped, problem-centered mind-sets to seek immediate application of what they learn. Emerging adults need to know what they will learn, why they will learn it, and how it will be learned. Finally, emerging adults are not yet intrinsically motivated to learn but instead are more extrinsically motivated (e.g., rewards, grades, etc...) to perform well in the class. By adopting a collaborative approach, instructors allow for the individual's self-concept to move from dependence to autonomy [21] and recognize that "adults generally become ready to learn when their life situation creates a need to know" [23].

Adult learners are internally motivated ((e.g., learning for leaning's sake) towards their subjects, and set short- and long-term goals actively. They are also are motivated by understanding the fundamentals of the topic based on their prior experiences [4, 37] and are more goal-directed than many traditional university students who pursue strategic or surface learning. As a result of adult learners' interest in and positive motivation for the subject, they are more willing than traditional students to increase time on task.

Opinions on the instructor's role in motivating traditional students vary widely. Some suggest that the instructor is primarily responsible for students' motivation [36], while others caution that instructors often lack sufficient understanding of their students' internal motivators [31]. Albert Einstein once said "I never teach my pupils. I only attempt to provide the conditions in which they can learn.” Smith [36] chronicles the early advocates of student engagement who argued that to teach is to engage students in learning where the instructor becomes less an imparter of knowledge and more a designer and facilitator of learning experiences and opportunities.

Although motivating students can be a difficult, a fundamental understanding of motivational principles is helpful for any instructor. By being aware of the motivational beliefs that students carry with them, instructors can assist students in adaptive interpretations of grades and understanding the value of exerting effort. Construction Management faculty can support students' motivational beliefs and academic achievement through the use of instructional practices that remind students about the important role that effort plays in success [37]. There are three main cognitive motivational theories: goal theory, expectancy value theory, and attribution theory that apply to students. 
In goal theory, motivation is induced by the discrepancy between their current condition as students and their future condition (i.e., goal) of being a practicing professional. Self-efficacy, or one's ability to succeed in a specific situation, plays a significant role in goal theory. A student's goals should be challenging but not be perceived as beyond their capability. If individuals must expend a great amount of time and effort to accomplish a goal, then they are more likely to choose an activity that they feel capable of performing successfully and that will lead to a more attainable valued outcome rather than wasting their time in a self-perceived futile endeavor [37].

The expectancy value theory of motivation holds that people engage in activities to accomplish goals because of the perceived value associated with their likely outcomes. For example, if the instructional topic is perceived by the student as relevant and valuable in attaining a sought after goal, the student will be motivated to perform [13, 31]. It's common in career and technical programs that too many students fail to see the relevancy in their fundamental math courses [18, 40]. In expectancy value theory, the motivation to engage in a behavior increases proportional to an individual's expectation that the behavior will lead to a valued outcome. As in goal theory, self-efficacy mediates this process as well, with individuals not pursuing a valued outcome if they perceive that they are unable to perform the requisite activity successfully [37].

Attribution theory focuses on how an individual attributes causes of past successes and failures, which thereby affect future choices of behaviors. If a person attributes the success of a past performance to hard work, they are likely to increase their efforts when challenged [33]. A learner's perception of the nature of intelligence has a significant influence on his/her interpretations of success or failure and the actions associated with each kind of outcome. Those with an incremental or growth mindset believe that intelligence can be grown and improved through the learning process; thus, they interpret failure as a need to exert additional effort or adopt different strategies. Those with an entity or fixed mindset believe that intelligence is unchangeable and are more likely to believe that poor performance is a result of a result of lacking intelligence [37].

Stamm [38] shares that creating a climate in which this learner-centered model of higher education is realized is not easy. The learner-centered classroom requires learner motivated teaching is a paradigm shift from the traditional university practices. Strategies for accomplishing this goal emphasize active and reflective learning trough project based learning, helping student make connections to see the relevancy of the subject, group collaboration, empowerment and promoting and assessing deep learning in contrast to surface or strategic learning. One means of empowering students in the decision making for the class is to offer them a choice to pursue assignments and the ability to pursue something of interest [14].

Ponton [33] and others highlighted that teachers affect student outcomes by communicating the purpose for developing particular skills and the criteria for mastering them. As instructors, we often profess that we do not want students to memorize but rather understand principles when solving problems. However, students often are quite successful for pursuing short-term 
memorization as it often leads to high marks on tests and good course grades. These learning strategies falter when students are confronted with more challenging problems requiring synthesis of what they have learned, such as when they are asked to put the pieces of a practically oriented puzzle together. In these cases, students' memorization-level knowledge is insufficient, as there are no quick fixes available. The solution in such scenarios is that the learner needs to change his or her way of looking at the problem from simply remembering how particular techniques work to understanding how and why a technique is applicable. McGuire [25] outlined "teaching students how to learn," touching on such topics as Bloom's taxonomy, motivations, and emotions to instill an appreciation for deeper learning strategies. Her discussion revealed many similarities to adult learning concepts.

Some knowledge can be difficult to acquire because it is conceptually difficult, alien, inert, tacit, or ritualized which cannot be gained from strategic or surface leaning [32]. Meyers and Land $[26,27]$ developed an educational theory on difficult to learn concepts as being thresholds that demarcate the familiar from the unfamiliar [22, 41]. Effective instructional techniques for threshold concepts involve partnering with students as co-inquirers and co-explorers and serving as a facilitator as students become more familiar with new learning strategies and other paths to successful learning outcomes [15]. One key is to stimulate the students to be prepared for class. For instance, instructors can identify the threshold concepts in a course and encourage open discussions by reducing the fear of asking questions in class. In doing so, both learner and instructor must acknowledge the non-linear nature of the learning trajectory and be open to different approaches. In addition, the learning of threshold concepts is enhanced through study groups and/or doing exercises collaboratively [5, 20]. Such approaches to teaching threshold concepts have the power to transform the way educators understand the teaching and learning process, with the instructor offering differing perspectives and alternate learning strategies in the context of student-centered learning.

Cline [7] found that the two most common educational approaches of construction educators were 1) a "transmission" or "stand and deliver" approach, where the teacher is a subject matter expert and accurately puts forward the content being taught in a manner that meets the needs of the learner, and 2) a developmental approach, where teaching is planned and conducted from the learner's point of view to facilitate learning. In the developmental approach, the teacher strives to help learners develop increasingly complex cognitive structures related to the content.

Pew [31] discussed challenges in adopting a more student-centered educational approach, cautioning higher education professionals about the risks of dismissing the pedagogy model in favor of the andragogy model.

\section{Methodology}

Since 2016, the instructional approach for a Construction Capstone course at BGSU has followed the active-learning principles of adult education by employing a series of surveys on students' 
prior experiences, interests, preferred topics, and preferred target projects to pursue in term length project-based learning (PBL) assignments. In addition to having course length PBL assignments mimic real world conditions, the Construction Capstone class has also entailed a review of prior course work in preparation for the American Institute of Constructors' (AIC) Associate Constructors examination. The project based assignment was designed to increase students' understanding of threshold concepts related to construction planning and schedule and risk management.

The central goal of this process was to move students from a reliance on passive, teachercentered instruction to a more active student-centered learning environment in which the instructor served more as a subject matter expert and facilitator in the learning process. Assessment of this approach was based on the level of student engagement with adult educational principles, student performance on the AIC examination, and the quality of the students' PBL submission. Assessments of the PBL submissions were largely gauged to the ability of the students to bring forward pertinent questions and to ultimately produce a synthesis deliverable that included a comprehensive project assessment and bid submission. Elements of the final submission have normally included completion of a prequalification statement, a conceptual estimate, a baseline construction schedule and schedule narrative, project specific risk analysis, safety job hazard analysis and a document akin to an escrow bid document or a job cost estimate breaking schedule activities into material, equipment and labor costs.

Special attention was paid to a series of threshold construction management concepts [39], including:

- Work sequencing

- Construction risk analysis

- Constructability reviews

- Fiscal management

- Innovative approaches to challenging conditions

- $\quad$ Transferring experience between projects, employing best practices, and avoiding adverse lessons learned

Outcome measures included the AIC test results, in-course and exit surveys of students, feedback during an open forum at the end of the course, and knowledge exhibited in a series of class discussions. Representatives from BGSU's Construction Management Industry Advisory Board participated in the open forum. The open forum discussions involved a P- $\Delta$ approach, in which students reported on positive aspects of the BGSU program and suggested areas for improvement. 


\section{Observations}

Andragogy was introduced to the BGSU construction management curriculum in 2016 in the senior level Construction Capstone course. Based on lessons learned in that course, efforts at applying andragogy principles continued in subsequent sessions of the capstone course and have recently been extended to courses in Construction Materials and Testing and Construction Methods and Practices.

The capstone class is now in its fourth iteration. The following discussion chronicles the evolution of the course and student performance on small group PBL assignments and an evaluation of their overall knowledge of construction management fundamentals.

The first class with a re-engineered format [3] had fourteen students and incorporated the following adult education learning techniques:

- The instructor solicited students' skills, interests, and career goals.

- Lecture periods were split between formal lectures and weekly small group work/progress sessions in a flipped classroom.

- Formal lectures were designed to spur student discussion and include examples of key principles that would be useful in students' cooperative education experiences.

- In a flipped classroom involving small discussion groups, students reported on their progress and any challenges in their project-based learning (PBL) term-length assignments. The instructor served as a coach or subject matter resource.

- $\quad$ Students were given the opportunity to select the target project for their project-based assignments.

- $\quad$ To help students prepare for the AIC exam, they completed self-paced and self-directed practice quizzes online.

In this first iteration, a single required in-class practice quiz served as an index for the students' preparation for the AIC exam.

After implementing these instructional approaches, the pass rate on the AIC increased to above $60 \%$ compared to prior historical levels near 30\%. Student performance ranged widely, with both notably high (94\% percentile nationally) and low ( $2^{\text {nd }}$ percentile) individual scores. None of the PBL small groups proposed a target project. However, collectively the class expressed an interest in a transportation project (small bridge) and a mixed use commercial development, which were ultimately defined by the instructor. Overall, student performance on two small PBL assignments was commendable - but there was one group that was a low-performing outlier in both cases. One of the important developments in this class was a high level of interactive class discussions that 1) facilitated learning of threshold and synthesis concepts and 2) led to a number of adjustments to the curriculum related to the Construction Estimating, Planning, \& Scheduling and Construction Methods and Practices courses [3]. 
Students cited the two most helpful elements of the course in preparing for the AIC were the elective practice quizzes (with a participation level of 62\%) and the lively class discussions. A common comment on the AIC exam was that the questions were fair, but that they differed from the study guide and practice quiz questions. Students suggested that more mandatory quizzes would be beneficial. Students also gave generally favorable, but mixed, reviews on the PBL based assignments.

The second iteration of the Construction Capstone had a significantly higher enrollment (31 students). The surveys and interviews continued and the repository of on-line quizzes was enlarged from ten to twenty-five modules and simplified, so that each on-line quiz could be completed within forty-five minutes. In response to prior student feedback, seven of these quizzes were mandatory and twenty-two were elective. Required quizzes included modules on planning \& scheduling, estimating, cost \& budgeting, and surveying, along with three comprehensive quizzes. Regarding the PBL assignment, again none of the student groups proposed their own target project. Therefore, again in discussion with the class the instructor selected a single project of greater size and complexity than in the prior version of the course, a soon to be bid mid-sized Ohio Department of Transportation bridge. The PBL assignment was further modified to require individual progress reports at the midterm when students were asked to report on any challenges, obstacles, or questions with regard to the assignment's end deliverables. To improve student learning of threshold and synthesis topics, a series of in-class exercises were introduced to address construction sequencing, risk management, and job cost management principles. In the small group discussions, the level of engagement declined significantly compared to the prior class. As consequence, additional in-class workshops were instituted to provide hands-on experience to buttress the student's skills related to threshold and synthesis concepts in construction sequencing, risk management, and job cost management.

For this second iteration, the pass rate on the AIC exam again surpassed the prior historical levels, but dropped to $50 \%$. A few students had exceptionally high scores, including the singlehighest percentile score ever recorded at BGSU at the $97^{\text {th }}$ percentile nationally, and there was a low outlier at the $4^{\text {th }}$ percentile. Student engagement on the PBL assignment faltered for all but one group, that submission whose attention to detail and quality far exceeded the others. This class cited the on-line practice quizzes as the single most valuable tool for the preparation for the AIC exam, followed by the in-class exercises. In the PBL interim progress reports, no concerns of note were offered. In spite of having seven required on-line quizzes. Overall participation in the elective on-line practice quizzes dropped to $44 \%$, with a dramatic decline on the elective quizzes

Students in the second iteration of the course suggested that even more mandatory quizzes would be beneficial. On average, the comments on the PBL assignment were neutral, with a high- and low-end outliers. The low-end outliers expressing that the PBL assignment was far beyond their interests and skill level. As with the prior iteration, the most common comment on the AIC exam 
was that the questions were fair, but that they differed from the study guide and on-line practice quiz questions.

The third iteration of the Capstone Course had fourteen students. By this time, the AIC had introduced two new study tools, including 1) an updated and much improved printed study guide, and 2) a series of ten on-line videos that closely followed the new study guide. The survey and interviews continued as before with nominal adjustments. The on-line practice quizzes were further refined, with five designated as required and twenty-four as elective. The student level of engagement with the elective quizzes was more closely monitored than in previous terms. Roughly three weeks before the AIC exam, the level of participation in the practice quizzes was significantly lower than in prior terms. The instructor reminded students of the feedback offered by prior students about the value of the practice quizzes, and the level of participation subsequently increased. Students were also more expressly advised of the purposes on PBL assignments and its role in their educational process.

In the third iteration of the course, again none of the PBL assignment groups chose their own target project. Instead relying on the instructor, who based on class discussions offered the small groups a choice of either a fast-tracked variant of the prior class assignments, a replacement Ohio Department of Transportation Bridge project, or a local school project that was approximately 25\% complete. Students also had the opportunity to review credible submissions from student groups in prior terms. The student formed their own groups with one electing the bridge and the other group pursued the school project

The students submitted individual progress reports at the midterm. The level of engagement on the PBL assignment varied between the groups with one group being actively engaged early on and other getting more engaged later in the process. Discussions in the PBL small groups meetings were disappointing. Select students were so disengaged that they never had visited their target-project job sites.

In this third iteration, the BGSU pass rate increased to 71\%, nominally higher than the national average. However, the high score for the class was markedly lower, at the $72^{\text {nd }}$ percentile nationally and the low score was at the $12 \%$ percentile. Students again suggested that more mandatory quizzes would be beneficial. Student performance on their PBL assignment was disappointing and student comments were again mixed but less positive than in prior terms.

In their interim PBL progress reports, students did not highlight any major concerns. However, in the exit surveys, a number of students noted that the selected projects were beyond their skill level and that more detailed instruction were required. Students again cited the on-line practice quizzes as most helpful aspect of the course in preparing for the AIC exam. Participation in the elective quizzes ultimately rose to $68 \%$. In exit discussions, several students revealed that they had created flash cards in attempts to memorize responses to the AIC study questions. 
The forth iteration of the Construction Capstone class is in-process with an enrollment of 32 students. The kick-off student surveys and inquiries were amended to identify student learning preferences with a simple exercise introduced by Conti [10]. From the beginning of this course students were coached on study strategies and urged to understand the questions, rather than rely on rote memorization.

One of the recommendations given was for students to review course-specific adult education learning strategies that predict student performance. The learning strategies and AIC score predictions offered for the Construction Capstone course is shown in Figures 1.

1. Always preview material before class.

2. Take lecture notes and go over them as soon as possible after lecture [35]

3. Try to do practice quizzes and assignments as if they were actual tests.*

4. Spend some time studying for this class at least 3-5 days per week (outside of class).

5. Take advantage of "low hanging fruit" that will be on the AIC exam.

6. Participate in a study groups.

7. Ask questions in class or go to office hours to discuss points of concern.

8. Take elective practice quizzes.*

9. Make diagrams (draw mental pictures) and mnemonics of the concepts discussed in class to help remember facts and equations.

10. Realize that you can do well on the AIC exam even if your early practice quiz scores are poor.

* Top recommendation from prior students in three recent sessions

$\underline{\text { Grade Prediction Index }}$

\begin{tabular}{|l|l|}
\hline $\begin{array}{c}\text { True Responses from } \\
\text { above }\end{array}$ & \multicolumn{1}{|c|}{ Predicted outcome } \\
\hline $6-10$ & Above $80 \%$ percentile \\
\hline $3-5$ & Border line \\
\hline Less than 3 & A foolish or risky bet \\
\hline
\end{tabular}

Figure 1 - Strategies to Predict your AIC Associate Constructors Exam Score

(Adapted from McGuire [25]) 
A significant development in this forth iteration of the course was that for the first time students in each of the five PBL groups selected their own target projects. All five groups developed a comprehensive set of deliverables for approval and produced meaningful bid packages that mirrored the guidelines in their Construction Methods and Practices text book [28] and the AIC study guide.

Aside from these notable changes, nominal refinements were made to the on-line practice quizzes and in-class exercises have increased. Six weeks prior to the AIC exam, the students' level of participation in the elective practice quizzes significantly lagged those of students in prior semesters (i.e., less than $5 \%$ level of participation). However, when confronted with these results, students markedly increased their participation in the practice quizzes to the point that just prior to the exam the participation rate approached that of the prior class (i.e., approximately a $60 \%$ participation level), as shown in Figure 2.

Students will take the AIC examination on April $7^{\text {th }}$. The results of their performance will be reported at the ASEE Annual Conference in Salt Lake City.

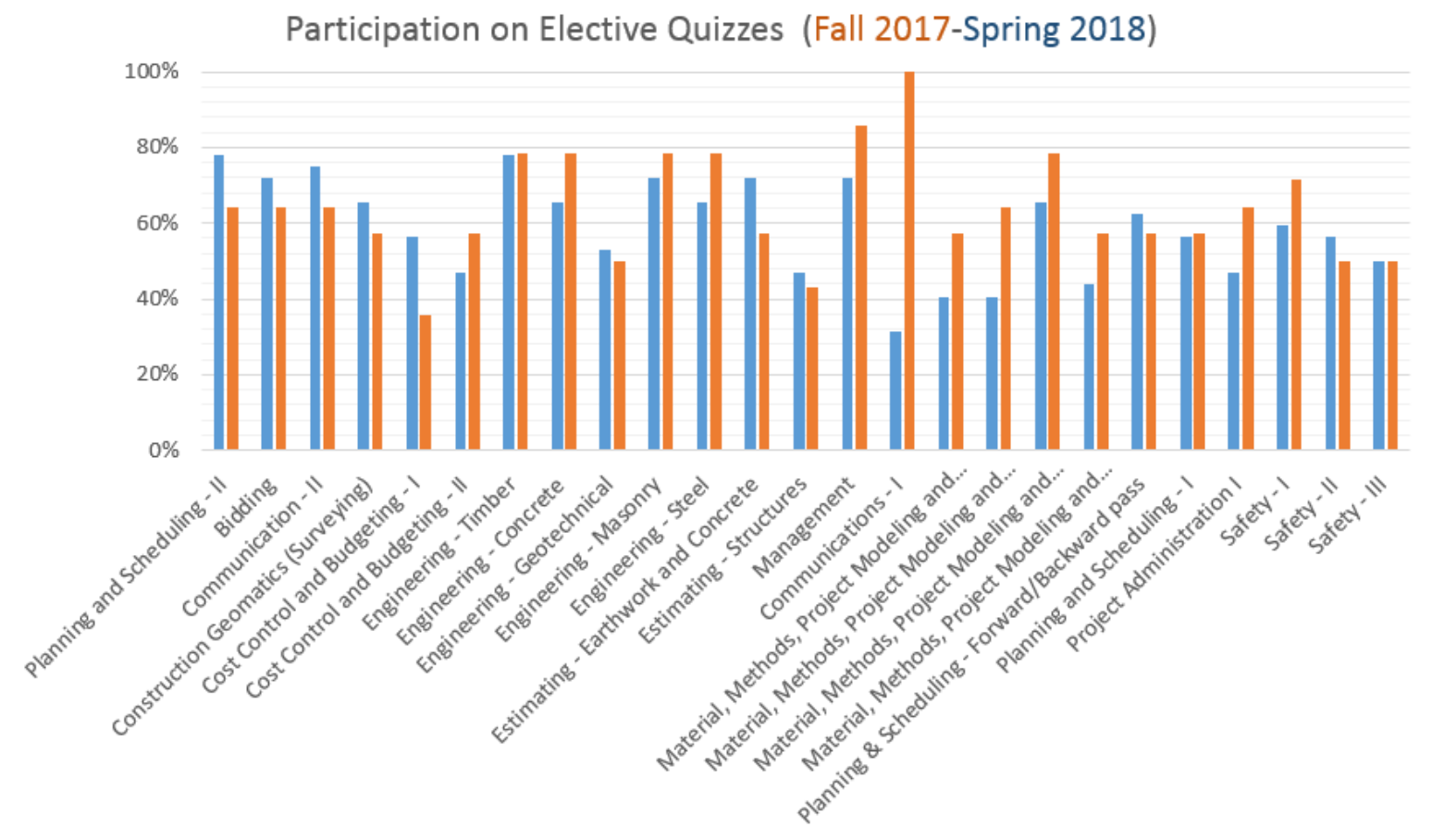

Figure 2: Comparison of student participation in elective AIC practice quizzes between the Fall 2017 and early efforts in the Spring 2018 classes

Figure 3 summarizes BGSU student progress on the AIC exam over the last few years. The improvement in performance at BGSU outstrips that of the national average and generally coincides with changes in instructional approaches at BGSU. 


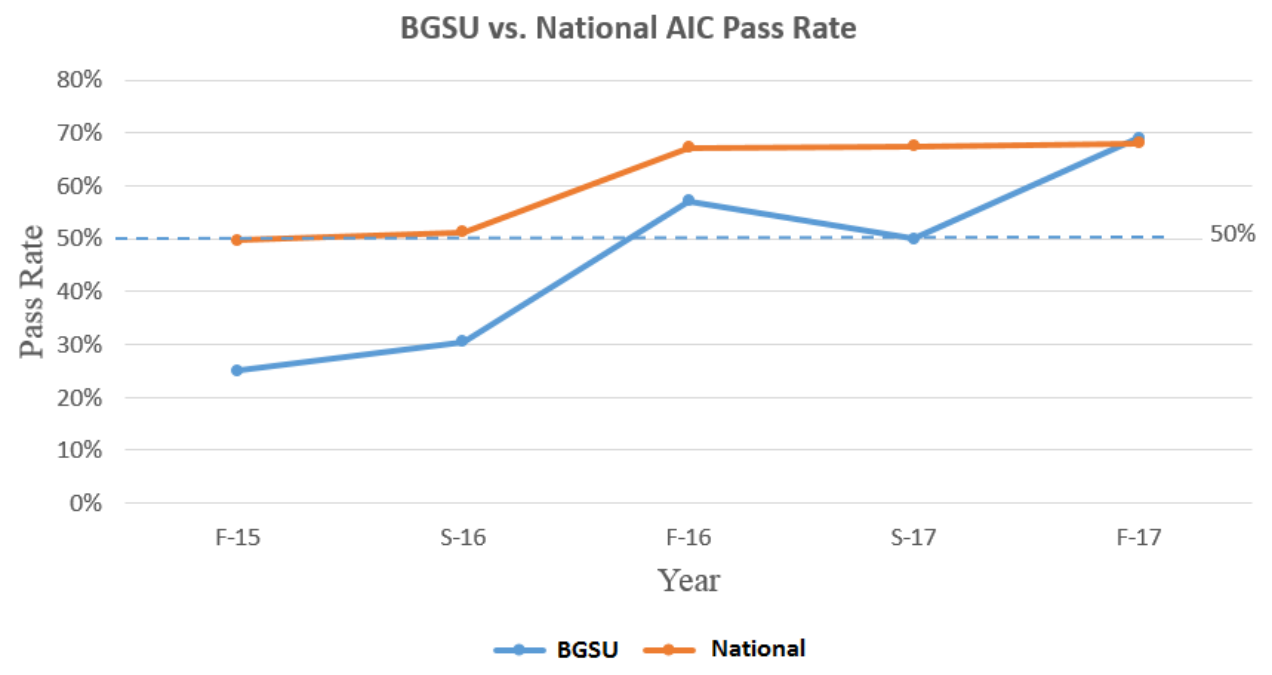

Figure 3. Recent historical performance of BGSU students on the AIC Associate Constructors exam

\section{Discussion:}

Pursuing adult education strategies within undergraduate courses at BGSU has met with mixed results. Whereas, there has been a significant improvement in the AIC test scores, which have risen to just above the national pass rate in the span of two years. In a class exercises to complement their PBL assignments, many students struggled with synthesis exercises in construction planning and scheduling commonly used in industry for construction sequencing. Many students also struggled with the concepts of identifying project risks and defining corresponding mitigation efforts and the development of a job cost estimate. Conveying these concepts took several iterations using the "Gilbane Card Trick" as described in AGC's Planning and Scheduling text book [17], the risk management instructions and spreadsheets developed by the Construction Industry Institute [11] and fundamental concepts of managerial accounting [42].

Although a few students embraced the concept of the instructor as a facilitator/coach, possessed the maturity to plan and manage a self-directed plan of study and were able capture some difficult to learn concepts, many students struggled. Student evaluations of the capstone course and an accompanying Senior Exit Survey have revealed a surprising number of students used memorization-focused learning strategies and express a preference for teacher-centered instructional approaches for both preparing for the AIC examination and for the synthesis PBL assignment which focused on skills development. These same trends are evident in other courses where adult learning principles have been employed.

The revised instructional strategies were designed to help students become cognitively active learners who know how to learn and not just what to learn. From the outset, stronger students embraced these concepts; but other students' efforts needed to be monitored and encouraged until they realized that their effort was their reward and consequently began to adopt some adult 
learning principles. The first notable sign of progress, beyond the stronger students, has be in the current fourth iteration of the capstone course, where student groups selected their own target PBL assignments. Other positive developments include some improvements in the quality and timeliness of submissions, ease of instruction on threshold concepts, and upon promoted by peers a higher level of participation in the elective practice quizzes.

The reasons for many students' lack of initiative were varied, but may have been largely due their unfamiliarity with the approach. In prior years, students did not have the kind of flexibility offered in the Construction Capstone course. A similar lack of initiative is evident in two other courses that introduced term-length assignments where adult learning approaches were employed. In a Construction Materials and Testing course, students were slow to select a construction failure or other topic related to the course content and failed to take advantage of resources readily available at the campus library. This same lack of initiative was evident in a Construction Methods and Practices course (project management) where many student found it challenging to communicate the relevancy of practices in a selection of signature past signature construction projects (e.g., Hoover Dam, Empire State Building and the original and recent construction of the Panama Canal) to current construction management practices.

The revised instructional strategies were designed to help students become cognitively active learners who know how to learn and not just what to learn. At this point. Without the benefit of the AIC results and student surveys, there are reservation on the success of this our most recent new tack. Nevertheless, a few thoughts on further refinements are under consideration.

1. Reduce the class size to no more that 20 to 25 students, as lower student to instructor ratio is needed to convey more challenging concepts and managed small group discussions.

2. Students' progress should be more closely monitored (as evidence in the need for reminders on critical resources and due dates)

3. Pursuing interdisciplinary training form other departments, such as the library on research resources

4. Introducing graded preview exercises to encourage advance preparation for lecture sessions

5. More deeply explore method to effectively increase student engagement

BGSU's President Rogers has shared that instructional practices at the university will strive to move beyond fundamental active learning approaches of group projects, class participation and flipped classrooms to creating new knowledge. This charge is within the reach of Construction Management faculty, as we strive to better prepare our students for an industry where each project is different, with unique requirements and resources, site-specific constraints, varying supply chains and 
Construction management is a profession where success is measured by the ability of an individual to stand on his or her own. In this profession, each project is different, with unique requirements and resources, site-specific constraints, and varying supply chains. Personnel and clients tend to change from one project to the next. These challenges demand skills far more complex than can be acquired by rote memorization. In short, in this profession, it is imperative that students possess critical thinking skills and the ability to ask the right questions during the planning and execution of the work.

\section{Conclusion}

The original focus of this paper was to report on how to effectively implement adult education or androgogical practices in an undergraduate curriculum believing that in doing, so students would be more successful in piecing together their coursework into a comprehensive assignment and being more able to capture difficult to learn concepts. Whereas, the objective is desirable, this paper hasn't answered that grand question.

Rather although there has been marked improvement in student performance in some respects, further investigations are needed. At this juncture, it's realized that as Stamm [38] offers "it's not easy". Aside from continual adjustments to improve instructional approaches, further studies are being considered to engage industry, educational authorities and construction management academics to identify and prioritize the most effective means of transitioning the emerging adult learner to embrace learning strategies will better serve them in their future careers.

As BGSU Construction Management program's expressed goal to more successfully produce construction management lieutenants, not corporals. Our efforts are fueled by a need to better prepare these newly minted lieutenants to rise in the ranks to be industry leaders.

\section{Cited works}

1. Abdelhamid, T. (2003) Evaluation of Teacher-Student Learning Style Disparity in Construction Management Education. American Society of Civil Engineers, Journal of Construction Education, 8

2. Arnett, J. J. (2000) Emerging adulthood: A theory of development from the late teens through the twenties. American Psychologist, 55, 469-480.

3. Austin, R. B. (2017) Reengineering BGSU's Construction Management Capstone, 2017 ASEE Annual Conference \& Columbus, $\mathrm{OH}$

4. Berg, D., Manib, H.S., Marinakis, Y., Tierneyc, R. and Walsh, S. (2015) An introduction to Management of Technology pedagogy (andragogy). Technological Forecasting \& Social Change $1001-4$ 
5. Berg, T., Erichsen, M. and Hokstad, L.F. (2016) Stuck at the Threshold, Which strategies do students choose when facing liminality with certain disciples at a business school?

6. Chan, S. (2010) Applications of Andragogy in Multi-Disciplined Teaching and Learning, Journal of Adult Education Volume 39, Number 2, 2010

7. Cline, R.C. (2011) Effective Construction Management Teaching Strategies, 2011 ASEE Annual Conference \& Exposition, Vancouver, BC

8. Conti, G.J. (1985) Assessing teaching style in adult education: How and Why. Lifelong Learning. 8(8)

9. Conti, G.J. (1985) The relationship between teaching style and adult student learning. Adult Education Quarterly. 35(4) pp 220-228

10. Conti, G.J. (2009) Development of a user-friendly instrument for identifying the learning preferences of adults. Teacher and Teacher Education. 45(4) pp 887-896

11. Construction Industry Institute. (2010) Management of Risks and Uncertainties, Research Summary 6-8, Construction Industry Institute, Austin, TX.

12. Dachner, A.M. and Polin, B. (2016) A Systematic Approach to Educating the Emerging Adult Learner in Undergraduate Management Courses. Journal of Management Education. 40(2) pp. $121-151$

13. Dembo, M. (2012) Motivation and learning strategies for college success: a focus on selfregulated learning, New York: Routledge

14. Dennis, S. (2017) Increase Student Motivation with More Choices. New England Journal of Higher Education, Feb 2017

15. Felten, P. (2016) On the Threshold with Students, Threshold Concepts in Practice, pp 107118

16. Forrest, S.P. and Peterson T.O. (2006) It's Called Andragogy. Academy of Management Learning \& Education, Vol. 5, No. 1 (Mar., 2006), pp. 113-122

17. Glavinich, Thomas, E., Construction Planning and Scheduling, 2nd edition, Associated General Contractors; Arlington, VA, 2004

18. Griese, B. (2017) Learning Strategies in Engineering Mathematics. Paderborn University, Germany: Springer Spektrum

19. Holt, E., Shaurette, M. and Chasek. C. (2016) A Comparison of Construction Management and Engineering Student Learning Styles, 2016 American Society of Engineering Education, 2016 Annual Conference \& Exposition.

20. King, C. and Felten, P. (2012) Threshold Concepts in Educational Development: An Introduction. Journal of Faculty Development. (26) 3, September 2012

21. Knowles, M. S. (1970). The modern practice of adult education. New York: Association Press. 
22. Knowles, M. S. (1980). The modern practice of adult education: From pedagogy to andragogy (revised and updated). Englewood Cliffs, NJ: Cambridge Adult Education.

23. Knowles, M. S., Holton, E. F., III, \& Swanson, R. A. (2012). The adult learner: The definitive classic in adult education and human resource development (7th ed.). New York, NY: Routledge.

24. Lin, C. and Tsai C. (2009) The Relationship between Students' Conceptions of Learning Engineering and their preferences for Classroom and Learning Environments, Journal of Engineering Education, 98(2), pp 193-204

25. McGuire, S.Y. (2015). Teach Students How to Learn, Sterling, Virginia, Stylus Publishing

26. Meyer J. H. F. and Land R. (2003) Threshold Concepts and Troublesome Knowledge: Linkages to Ways of Thinking and Practicing in Improving Student Learning - Ten Years On. C. Rust (Ed), OCSLD, Oxford

27. Meyer J. H. F., Land R. and Baillie, C. (2010) Threshold Concepts and Transformational Learning. Sense Publishers: Rotterdam, Netherlands

28. Mincks, W.R. and Johnston, H. (2011) Construction Jobsite Management, 3rd Edition Delmar Centage Learning, Clifton Park, NY

29. National Survey of Student Engagement: The College Student Report-2016 Annual Report, Bloomington, Ind.: Center for Postsecondary Research, Indiana University, 2016.

30. Nelson, L., Padilla-Walker, L., Carroll, J., Barry, C. Madison, S. and Badger, S. (2007) "If You Want Me to Treat You Like an Adult, Start Acting Like One!” Comparing the Criteria That Emerging Adults and Their Parents Have for Adulthood, Journal of Family Psychology 2007, Vol. 21, No. 4, 665-674

31. Pew, S. (2007) Andragogy and Pedagogy as Foundational Theory for Student Motivation in Higher Education, Student Motivation, InSight: A Collection of Faculty Scholarship, v2 pp 14-25

32. Perkins, D. (1999). The many faces of constructivism. Educational Leadership, 57, 6-11.

33. Ponton, M.K., Edmister, J.H., Ukeiley, L.S. and Seiner, J.M. (2001) Understanding the Role of Self-Efficacy in Engineering Education, Journal of Engineering Education, Volume 90, Issue 2 pp 247-251

34. Pratt, D. (1988) Andragogy as a Relational Construct, Adult Education Quarterly, 38(3) pp $160-181$

35. Slotte V. and Lonka K. (1999). Review and Process Effects of Spontaneous Note-Taking on Text Comprehension. Contemporary Educational Psychology. 24(1), pp: 1-20.

36. Smith, K., Sheppard, S., Johnson, D. and Johnson, R. (2005) Pedagogies of Engagement: Classroom-Based Practices, Journal of Engineering Education, 94(1), pp 87-101

37. Snyder, K.E., Barr, S.M., Honken, N.B., Pittard, C.M. and Ralstona, PAS (2018) Navigating the First Semester: An Exploration of Short-Term Changes in Motivational Beliefs Among Engineering Undergraduates, Journal of Engineering Education, 07(1) 
38. Stamm, L. (2011), Leading the Learner-Centered Campus, Journal of College and Character, 12(4), pp 1-6

39. Tatum, C.B. (2018) Learning Construction Engineering: Why, What, and How?, J. Constr. Eng. Manage., 2018, 144(3)

40. Wang, X., Wang, Y. and Prevost, A. (2017) A Researcher-Practitioner Partnership on Remedial Math Contextualization in Career and Technical Education Programs, New Directions for Community Colleges, 178 (3), pp 23-34

41. Zepke, N. (2013) Threshold concepts and student engagement: Revisiting pedagogical content knowledge. Active Learning in Higher Education 14(2) 97 -107

42. Adrian, J and Adrian, D. (1999) Construction Accounting, Financial, Managerial, Auditing and Tax, Stipes Publishing, Champaign, Il. 